\title{
Cheliped transformation in the swimming pea crab Tritodynamia horvathi Nobili
}

\section{Takuya Otani and Tohru Takahashi}

Abstract. - Previously, the species Tritodynamia intermedia has been distinguished from $T$. horvathi based on the number of teeth on the dactylus of the cheliped. However, it was reviewed that $T$. intermedia is synonymous with $T$. horvathi. The number of teeth on the chelipeds of $T$. horvathi with growth was investigated in the laboratory and the field. Crabs from the first to the third stages had two teeth on the proximal section of the dactylus of the cheliped whilst the fifth or later stage crabs had only one tooth at the same site on the cheliped. Both types of chelipeds were observed in the fourth stage crabs. In the natural population, carapace width of crabs with 2 teeth chelipeds were less than $12.3 \mathrm{~mm}$, and that with one tooth chelipeds larger than $5.4 \mathrm{~mm}$. Furthermore, sexual differences in the width of the abdomen occurred at the fourth crab stage.

\section{Introduction}

The pinnotherid crab Tritodynamia horvathi (Nobili, 1905) inhabits inland seas of east Asia: Japan, Korea and China. This species shows a curious behavior of swimming and swarming in the summer (Miyauchi, 1935; Sakai, 1939; Kamita, 1941; Arakawa, 1973; Miyake, 1976; Sakai, 1976; Funakoshi, 1989).

Besides T. horvathi, another swimming pea crab, $T$. intermedia, has been established in the past (Shen, 1935). Shen (1935) distinguished $T$. intermedia based on the tooth number on the dactylus of the cheliped; i.e., T. horvathi has one tooth on the proximal section of the dactylus whilst T. intermedia has two teeth. However, Sakai (1976) recognized that $T$. intermedia was synonymous with $T$. horvathi, because swarms of $T$. horvathi sometimes includes individuals of both one and two teeth types.

In 1989, we succeeded in rearing an entire generation of $T$. horvathi (see Otani et al., in press) and found that young $T$. horvathi have two teeth on the proximal section of the dactylus. This paper describes the transformation of the chelipeds and abdomen with the growth.

\section{Materials and Methods}

Specimens of each crab stage, which were reared from zoeae hatched in the laboratory in 1989 , were fixed with $10 \%$ formalin for 24 hours and then preserved in $70 \%$ ethyl alcohol. The number of teeth on the proximal section of the dactylus of the chelipeds was counted. As an index of the level of sexual maturity of females, the ratio of the abdominal width against carapace width (AR) was calculated as follows:

$$
\mathrm{AR}=100 \times \mathrm{AW} / \mathrm{CW}
$$
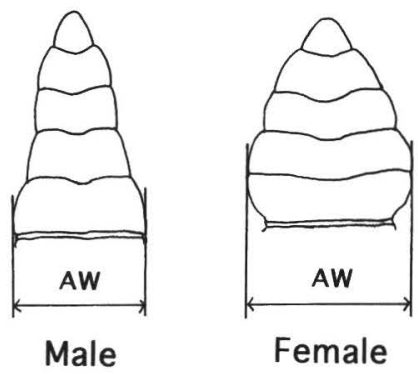

Fig. 1. Position of measurements of the widest segment of the abdomen (AW) in T. horvathi. 

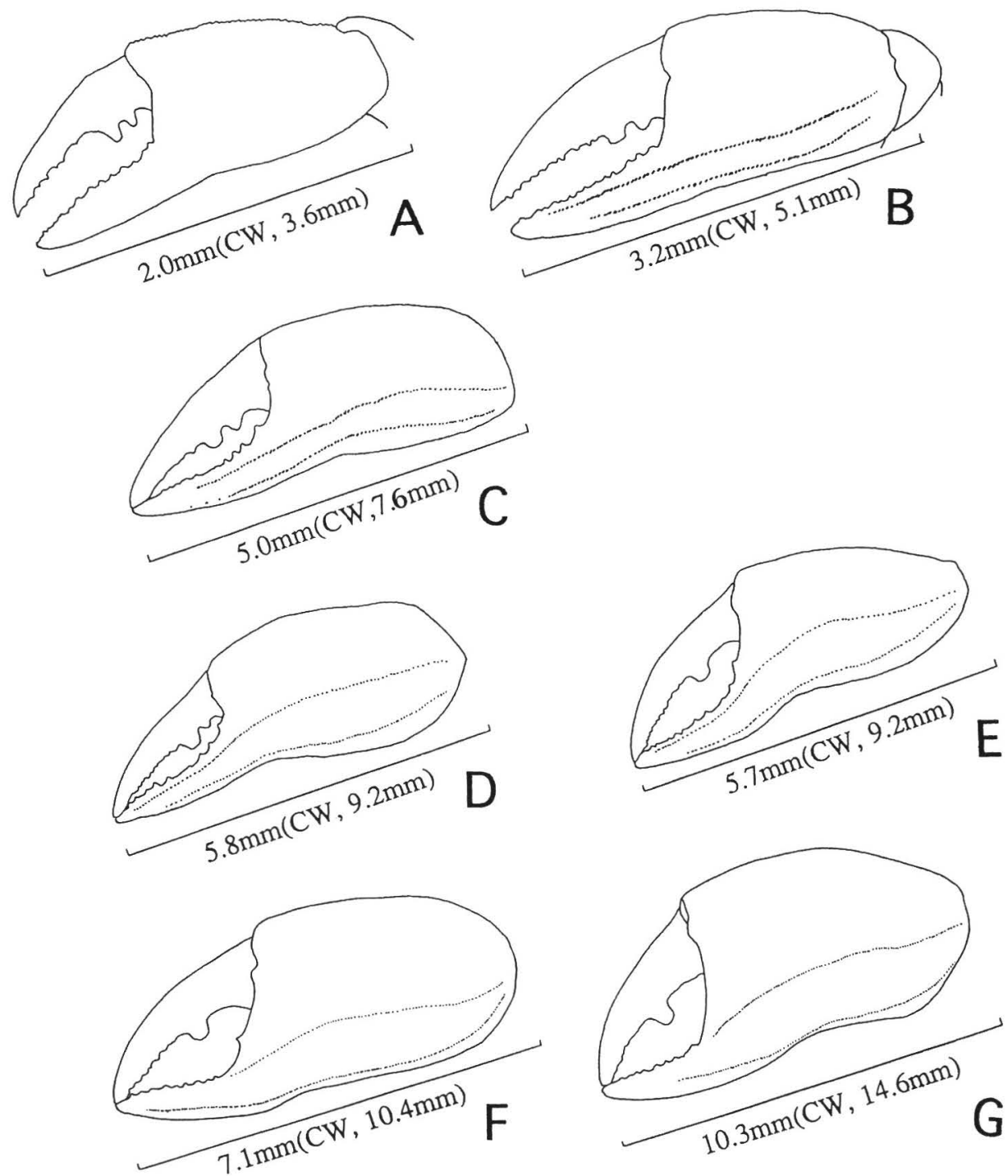

Fig. 2. Chelipeds of each stage crab. A, first crab; B, second crab; C, third crab; D, fourth crab (two teeth type); E, fourth crab (one tooth type); F, fifth crab; G, ovigerous female.

where $\mathrm{AW}$ is the abdominal width, $\mathrm{CW}$ is the carapace width.

AW was measured at the widest segment of the abdomen under a stereoscopic microscope (Fig. 1). Chelipeds were observed and classified into either one or two teeth types based on their morphology. Cheliped lengths and CW were also measured to the nearest $0.1 \mathrm{~mm}$ by hand- held calipers under a stereoscopic microscope.

Further, chelipeds of 250 wild sampled crabs were examined. Crabs were captured by hand net from Yatsushiro Sound on August 7, 16, and October 21, 1989.

Crab stages were estimated from the results on growth of Otani et al. (in press) as follows. C1, 3.2-3.7 mm; C2, 5.0-5.6 
Table 1. The number of teeth on the proximal section of dactylus of cheliped of each stage crab, numerals indicates the number of individuals with each cheliped type.

\begin{tabular}{|c|c|c|c|c|c|}
\hline \multirow{2}{*}{$\begin{array}{l}\text { Number } \\
\text { of teeth }\end{array}$} & \multicolumn{5}{|c|}{ Crab stage } \\
\hline & $\mathrm{C1}^{*}$ & $\mathrm{C} 2{ }^{*}$ & C3 & $\mathrm{C} 4$ & C5 \\
\hline One & 1 & 0 & $\begin{array}{ll}0 & 0 \\
9 & 0\end{array}$ & $\begin{array}{l}\text { o } 4 \\
\text { † } 12\end{array}$ & $\begin{array}{l}\text { o } 8 \\
\text { † } 12\end{array}$ \\
\hline Two & 25 & 20 & $\begin{array}{l}\delta 12 \\
\$ 20\end{array}$ & $\begin{array}{ll}0 & 0 \\
+ & 2\end{array}$ & $\begin{array}{ll}0 & 0 \\
o & 0\end{array}$ \\
\hline Three & 0 & 0 & $\begin{array}{ll}0 & 0 \\
0 & 1\end{array}$ & $\begin{array}{ll}\delta & 0 \\
q & 0\end{array}$ & $\begin{array}{ll}0 & 0 \\
9 & 0\end{array}$ \\
\hline Total & 26 & 20 & 33 & 18 & 20 \\
\hline
\end{tabular}

*Sex unknown

$\mathrm{mm}$; C3, 6.4-7.6 mm; C4, 8.5-9.8 mm; C5, $10.3-12.3 \mathrm{~mm}$.

Results

Table 1 shows the teeth number on the chelipeds of each stage of crab reared in the laboratory. Crabs from the first to the third stages (3.2-7.6 $\mathrm{mm}$ in $\mathrm{CW}$ ) had two teeth on the proximal section of the dactylus of the chelipeds with only two exceptions in the 79 samples. Of the two exceptions, a first stage crab had chelipeds with only one tooth type and another third stage crab had chelipeds of a type with three teeth. Two females (11.1\%) of the examined 18 fourth stage crabs (8.5$9.8 \mathrm{~mm}$ in $\mathrm{CW}$ ) had two teeth chelipeds and the others $(88.9 \%)$ had one tooth chelipeds. All of the fifth (10.3-12.3 $\mathrm{mm}$ in CW) and later stage crabs had one tooth chelipeds. No crabs reared in the laboratory were observed to possess chelipeds with heteromorphic chelipeds, i.e., one cheliped with one tooth type and the other with two teeth. No conspicuous sexual difference was observed in the forms of chelipeds.

Figure 2 shows the cheliped form of each crab stage reared in the laboratory. Chelipeds with two teeth had a straight dactylus and a thin propodus whilst the chelipeds with one tooth had a curved

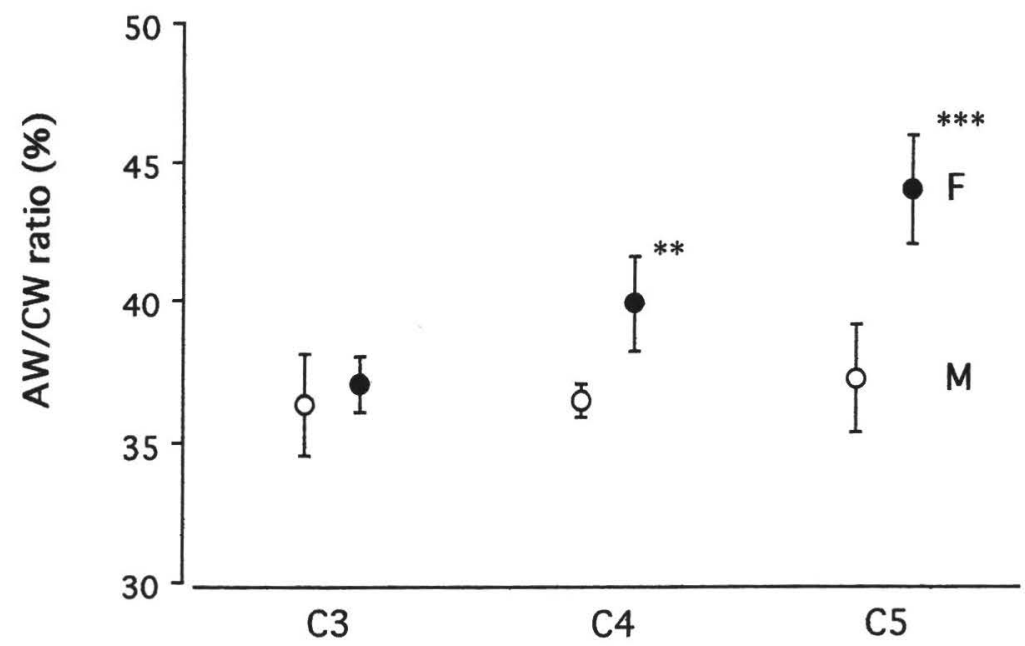

\section{Crab stages}

Fig. 3. Ratio of abdominal width against carapace width (AR) from third to fifth stage crab for male $(O)$ and female $(O)$ crabs. The points are means and error bars represent the standard deviation. C3; third crab, C4; fourth crab, C5; fifth crab. Asterisks show that ARs of females are significantly larger than those of males. $* *(P<0.01), * * *(P<0.001)$. 


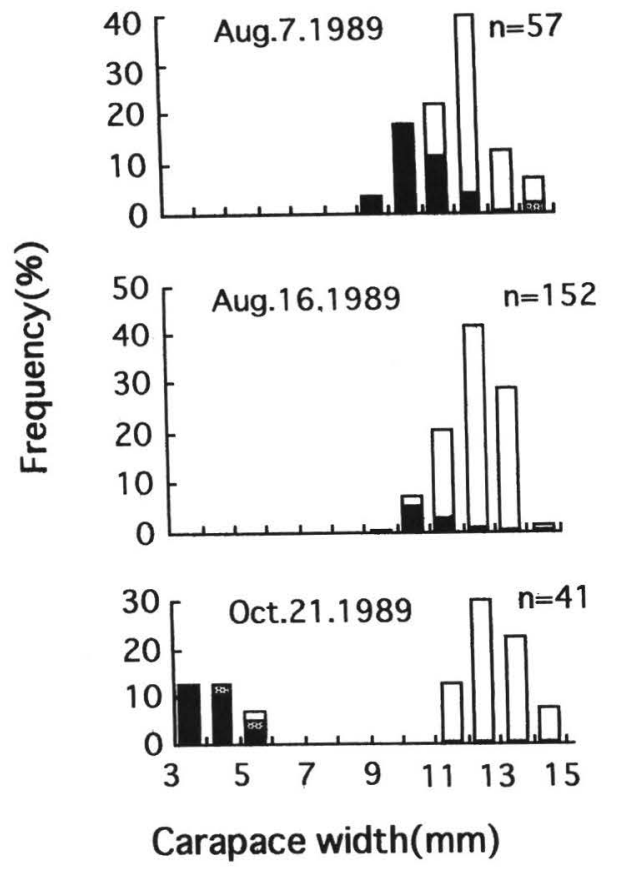

1 tooth

留 1 and 2 teeth 2 teeth

Fig. 4. Size frequency distribution of $\mathrm{CW}$ of wild crabs with two types of chelipeds collected at Yatsushiro Sound.

dactylus and a thick propodus.

ARs of the third to fifth stage crabs are shown in Fig. 3. Sexual differences in AR became marked in the fifth stage crabs. Therefore, the transformation of the cheliped morphology is also synchronized with the appearance of the secondary sexual characteristics in the abdomen.

Figure 4 shows the incidence of the two types of chelipeds in the natural population. Carapace width of the crabs collected on August 7 ranged from 9.5 to 14.5 $\mathrm{mm}$. Twenty crabs (mean: $10.9 \mathrm{~mm}$, range: $9.5-12.3 \mathrm{~mm}$ ) had two teeth chelipeds, and one crab (14.3 mm) had heteromorphic chelipeds; one cheliped with one tooth and the other cheliped with two teeth. The other $36 \mathrm{crabs}$ (mean: $12.6 \mathrm{~mm}$, range: $11.0-14.5 \mathrm{~mm}$ ) had chelipeds with only one tooth. Of the 152 crabs collected on August 16, 13 crabs (mean: $10.9 \mathrm{~mm}$, range: $9.7-12.0 \mathrm{~mm}$ ) had two teeth chelipeds, and the other 139 crabs (mean: 12.5 $\mathrm{mm}$, range: $10.1-14.2 \mathrm{~mm}$ ) had one tooth chelipeds. Crabs collected on October 21 showed two clearly divided cohorts. CW of one cohort ranged from 3.6 to $5.4 \mathrm{~mm}$ (mean: $4.2 \mathrm{~mm}$ ); nine crabs (mean: 3.9 $\mathrm{mm}$, range: $3.6-4.2 \mathrm{~mm}$ ) had two teeth chelipeds, two specimens (4.3 and 5.4 $\mathrm{mm}$ ) had heteromorphic chelipeds; one cheliped with one tooth and the other cheliped with two teeth, and another specimen $(5.4 \mathrm{~mm})$ had one tooth chelipeds. Twenty nine crabs of the other cohort (mean: $12.8 \mathrm{~mm}$, range: $11.3-14.4 \mathrm{~mm}$ ) all had one tooth chelipeds only.

Consequently, two teeth type crabs sampled from the wild were smaller than $12.3 \mathrm{~mm}$, and one tooth type crabs were larger than $5.4 \mathrm{~mm}$ in $\mathrm{CW}$. The $\mathrm{CW}$ range of crabs with the two different types of chelipeds in the natural population was wider in natural than in reared samples.

\section{Discussion}

The transformation of chelipeds occurred accompanied with the molts from third to fourth or fourth to fifth crab stage in the laboratory. In addition, in the natural population the number of teeth of the chelipeds decreased over similar sizes from two to one teeth as in the laboratory reared crabs, although several exceptions were observed.

As is common in all living material, there is variation between individuals. In the reared crabs, we noted a first stage crab (CW $3.4 \mathrm{~mm}$ ) with only one tooth chelipeds. Further, a second stage crab (CW $5.4 \mathrm{~mm}$ ) with one tooth chelipeds was also found in the natural population.

We collected first or second stage crabs in Yatsushiro Sound on October 21. The occurrence of young crabs support the idea that the first breeding season occurs in the natural population in early autumn (Otani et al., in press). 
T. horvathi was first described from a specimen $10.7 \mathrm{~mm}$ in $\mathrm{CW}$ to have one tooth type chelipeds (Nobili, 1905). After that, Shen (1935) established T.intermedia (CW 10.0 and $20.5 \mathrm{~mm}$ ) based on the number of teeth on the proximal section of the dactylus of the chelipeds. However, Sakai (1976) found that T. intermedia is synonymous with $T$. horvathi, because swarms of $T$. horvathi sometimes included individuals with two teeth type chelipeds. However at that time it was not realized that the number of teeth of the chelipeds can decrease with growth from two to one tooth type chelipeds. As a result, our observations support Sakai's view (Sakai, 1976) that $T$. horvathi and $T$. intermedia are synonymous.

\section{Acknowledgments}

We thank Dr. T. Yamaguchi, Aitsu Marine Biological Station, Kumamoto University, and Mr. M. Matsuo for helpful advice of our research. We wish to thank Dr. C. P. Norman, Japan Scientific Texts, Dr. R. B. Manning, Smithsonian Institution and Dr. M. Minagawa, Seikai National Fisheries Research Institute, for their critical reading of the manuscript.

\section{Literature Cited}

Arakawa, K., 1973. Notes on unusual occurrence of "Red water" caused by a shoal pinnotherid crab, Tritodynamia horvathi NOBILI, off the coast of Hiroshima Prefecture in 1971. Hiroshima Prefectural Fisheries Experimental Station, 4: 129131. (In Japanese with English abstract)
Funakoshi, S., 1989. Outbreak of Tritodynamia horvathi in summer of 1988 in Ise Bay. Bulletin of the Japanese Society of Fisheries Oceanography, 53: 101-102. (In Japanese)

Kamita, T., 1941. Studies of the Decapod Crustaceans of Chosen. pt. 1. Crabs. The Fisheries Society of Chosen, Keijo, pp. 1289.

Miyake, S., 1976. Occurring cycle of Mirokugani, Tritodynamia horvathi in Ariake Sound. Will the next outbreak occur in 1977? Doubutsu to Shizen, 6(1): 9-12. (In Japanese)

Miyauchi, S., 1935. Studies on sabagani (Tritodynamia horvathi). Suisangakkaiho, 6(4): 244-245. (In Japanese)

Nobili, G., 1905. Tritodynamia horvathi Nob. nuovo decapodo del Giapone. Annales Musei Nationalis Hungarici, 3: 407-413.

Otani, T., Takahashi, T., \& Matsuura, S., 1996. Growth and breeding of the swimming pea crab Tritodynamia horvathi reared in the laboratory. Fisheries Science, 62(4).(in press)

Sakai, T., 1939. Studies on the crabs Japan. IV. Barachygnatha, Brachyrhyncha. Yokendo, Tokyo [741pp., 70pls.].

$\longrightarrow, 1976$. Crabs of Japan and adjacent seas. Kodansha, Tokyo [In 3 volumes; (1) English text, xxxix + 733pp. (2) Plates volume, 16pp., 251pls. (3) Japanese text, 461 pp.].

Shen, C. J., 1935. On some new and rare crabs of the families Pinnoteridae, Grapsidae and Ocypodidae from China. Chinese Journal of Zoology, 1: 19-40.

Addresses: (TO) Nagasakiken Fisheries Co., Ltd., Kosaza, Nagasaki 857-04, Japan; (TT) Department of Fisheries, Kyushu University, Hakosaki, Fukuoka 812, Japan.

E-mails: (TO) mxg02514@niftyserve. or.jp; (TT) takahasi@agr.kyushu-u.ac.jp 